\title{
Meeting Report: Research Topics in Gastrointestinal Disease V
}

\author{
Organizing Committee: \\ Gordon R Greenberg MD, University of Toronto, Toronto, Ontario \\ Ken Croitoru MD FRCP, McMaster University, Hamilton, Ontario \\ Kris Chadee PhD, Chair, CAG Research Committee; University of Calgary, Calgary, Alberta \\ Paul Sinclair, Executive Director, CAG
}

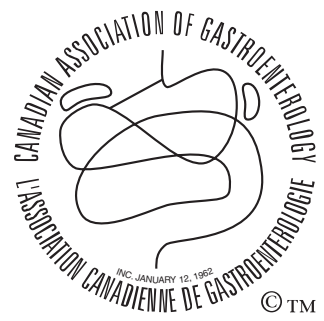

En français voir page 47
$\mathrm{R}$ ecent advances in gastrointestinal (GI) diseases are a direct result of the rapid development of fundamental research using cellular and molecular biology approaches. These approaches have helped to define the normal physiological processes of the GI tract and the pathogenesis of disease mechanisms. The Canadian GI research communities are world leaders in contributing to these efforts in all disciplines that are relevant to GI disease. This success has been achieved by fostering an excellent cohort of graduate and postgraduate research trainees involved in GI research at institutions across Canada. Many of these trainees are funded by the Canadian Association of Gastroenterology (CAG) in collaboration with the Canadian Institutes of Health Research, a number of industry partners and the Crohn's and Colitis Foundation of Canada.

In recognition of the value of the Canadian GI trainees' outstanding research contributions, and to promote and encourage the continued efforts of the graduate and postgraduate research trainees in basic and clinical sciences, the CAG, in conjunction with AstraZeneca Canada Inc and the Canadian Institutes, held the Fifth Symposium on Research Topics in Gastrointestinal Disease, October 21 to 23, 2005 (Figure 1). The goal of this meeting was to provide research trainees with an opportunity to informally present their original on-work research to their peers and to a selection of faculty from across Canada. In this forum, trainees actively participated in the discussions of papers in an open setting. This year's program consisted of a series of superb presentations describing cutting-edge research with 38 podium scientific presentations of basic and clinical GI-related research, covering mechanisms of gut inflammation, pathogens that initiate inflammatory processes and cancer, epithelial barrier functions, hormones that modulate gut responses, Helicobacter pylori and its disruption on intracellular signalling mechanisms, and pathogens that initiate gut proinflammatory and defensive functions. A new addition this year was a superb keynote lecture on "immune regulation in the 21 st century" outlining the importance of $\mathrm{T}$ regulatory cells in inflammatory bowel disease, given by Dr Ken Croitoru.

A major success of the meeting was that it also provided a venue in which trainees could meet their peers from across Canada and initiate collaborative opportunities, thus developing contacts for their future research career and the future of Canadian GI research. This aspect was commented upon by trainees attending for the second time and in the overall feedback responses we received during the meeting. All participants evaluated the meeting as excellent and described the experience as rewarding and a superb learning forum. Thus, as a result of this enormously successful symposium, the organizing committee, the CAG and AstraZeneca Canada Inc are committed to holding this meeting on a regular basis. Plans are already underway for a fall 2006 meeting, in which, once again, research abstract submissions relating to all facets of GI health and disease will be welcomed. Canadian investigators with basic and clinical GI research programs are strongly requested to lend support to this important endeavour by encouraging the participation of their trainees and graduate students.

ACKNOWLEDGEMENTS: The organizers would particularly like to thank AstraZeneca Canada Inc for their generous support of this meeting, the fifth of its kind in a series that will continue to advance gastroenterology in Canada. In addition, we wish to thank the invited faculty, Mark Ropeleski, Isabella Tai and Nicola Jones for their commitment and valuable contributions to this meeting.

\section{The CAG is proud to acknowledge its Benefactor Corporate Sponsors:}

\begin{abstract}
Abbott Laboratories Ltd
Janssen-Ortho Inc
\end{abstract}

\section{AstraZeneca Canada Inc \\ Pfizer Canada Inc}

Axcan Pharma Inc

Schering Canada Inc 


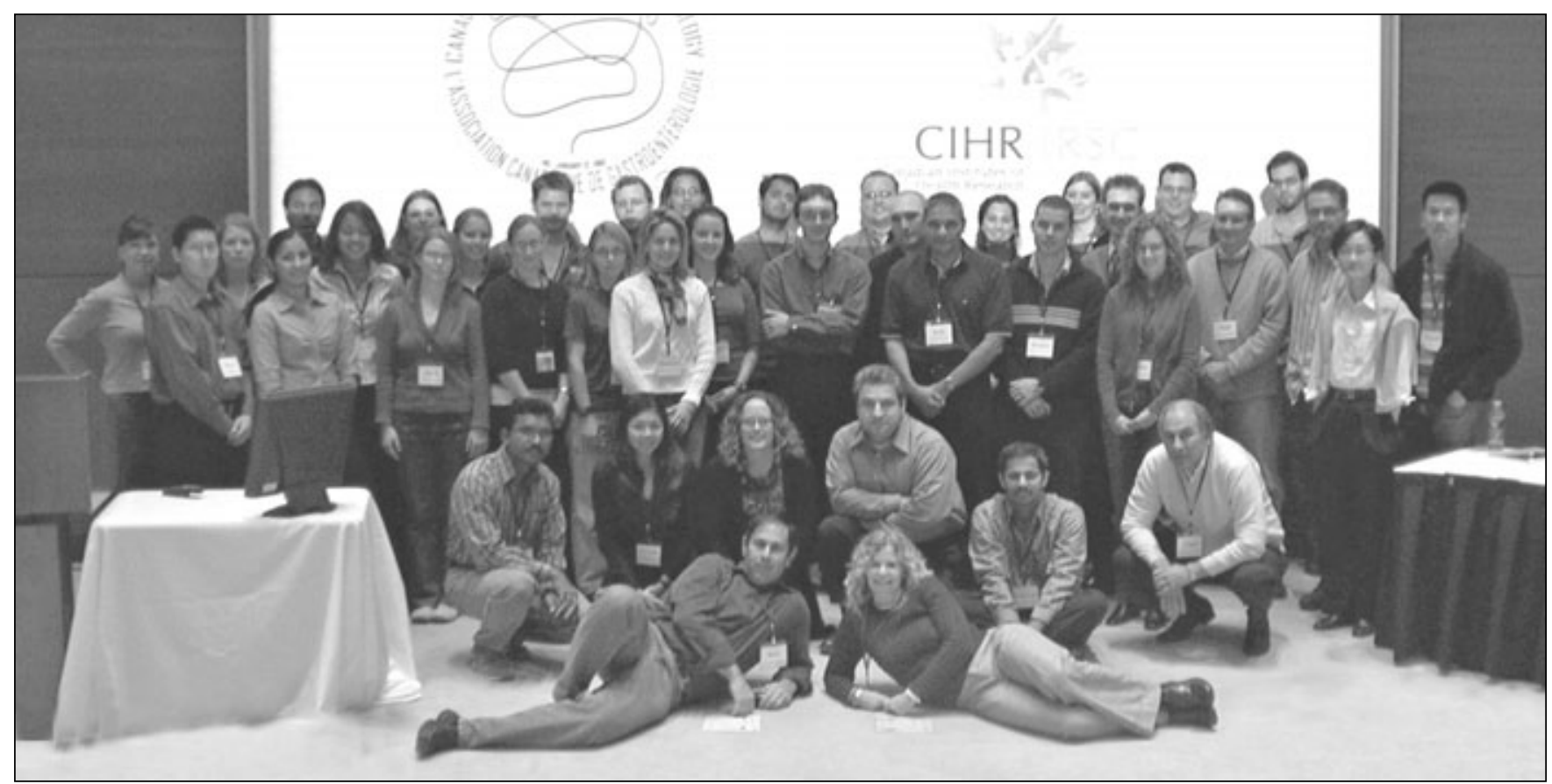

Figure 1) Participants and faculty in the Fifth Symposium on Research Topics in Gastrointestinal Disease, October 21 to 23,2005 / Participants et professeurs présents au $V^{e}$ Colloque sur les sujets de recherche en gastro-entérologie, tenu du 21 au 23 octobre 2005. Participants et participantes : Jody Backer, Edmonton, Alberta; Anders Bondo Dydensborg, Sherbrooke, Quebec; Dana Bronte-Tinkew, Scarborough, Ontario; Jackie Caldwell, Waterdown, Ontario; Philippe Cammisotto, Montreal, Quebec; Nicolas Cenac, Calgary, Alberta; Hugo Diaz-Silvestre, Edmonton, Alberta; Andrea Dmytrash, Edmonton, Alberta; Kevin Donato, Richmond Hill, Ontario; Julia Ewaschuk, Edmonton, Alberta; Andrew Flynn, Calgary, Alberta; David Gagné, Sherbrooke, Quebec; Mélanie Gareau, Hamilton, Ontario; Christina Hirota, Hamilton, Ontario; Marinella Holzhausen, Calgary, Alberta; Narveen Jandu, Toronto, Ontario; Srinivas Kammanadiminti, Calgary, Alberta; Dirk Lange, London, Ontario; Manigandan Lejeune, Calgary, Alberta; Gareth Lim, Toronto, Ontario; Kristen MacEachern, Oakville, Ontario; Stacey Marlow, Kingston, Ontario; Gary Martin, Calgary, Alberta; Elana Maser, Toronto, Ontario; Sean McDonagh, Toronto, Ontario; Alexandra Merkx-Jacques, London, Ontario; Kaitlin Naugler, Kingston, Ontario; Robin Persaud, Hamilton, Ontario; Kelly Plaku, Calgary, Alberta; Roger Stanzel, Kingston, Ontario; Amy Stillar, Calgary, Alberta; Veronica Swystun, Calgary, Alberta; Michelle Tang, Vancouver, British Columbia; Aaron Teitelbaum, North York, Ontario; Jacques Van Der Merwe, Calgary, Alberta; SRV Vijayakumar, London, Ontario; Thomas Walters, Toronto, Ontario; Ron Wells, Kingston, Ontario. Faculty / Professeurs et professeure : Dr Kris Chadee, Calgary, Alberta; Dr Nicola Jones, Toronto, Ontario; Dr Gordon R Greenberg, Toronto, Ontario; Dr Mark Ropeleski, Kingston, Ontario; Dr Ken Croitoru, Hamilton, Ontario; Dr Isabella Tai, Vancouver, British Columbia 


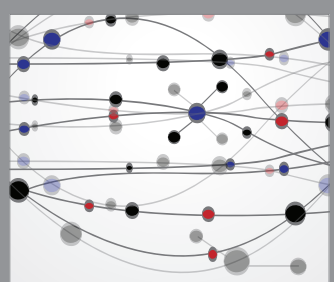

The Scientific World Journal
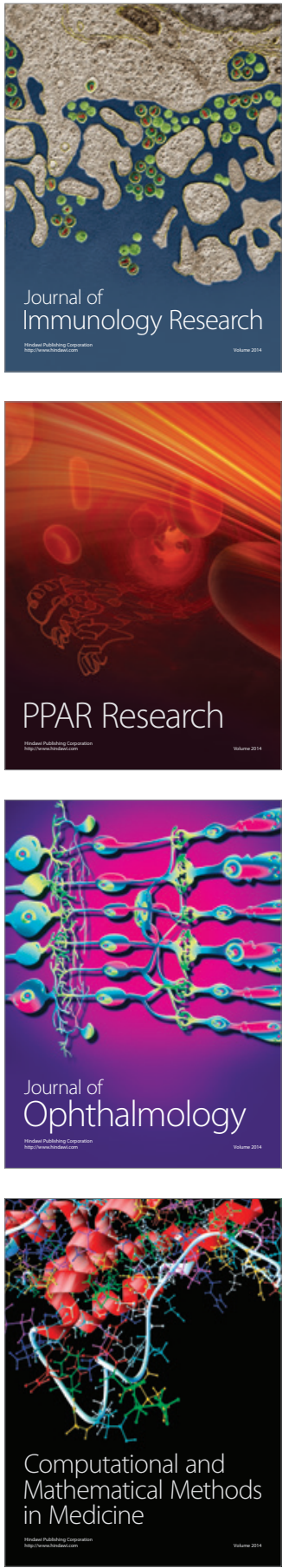

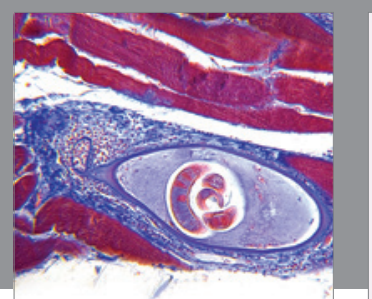

Gastroenterology Research and Practice

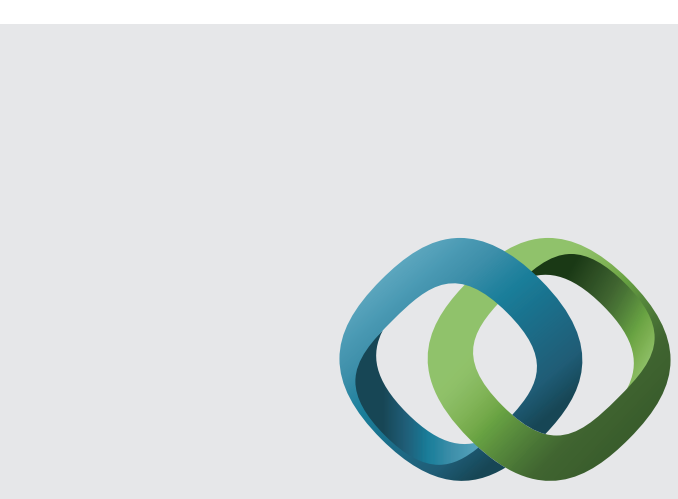

\section{Hindawi}

Submit your manuscripts at

http://www.hindawi.com
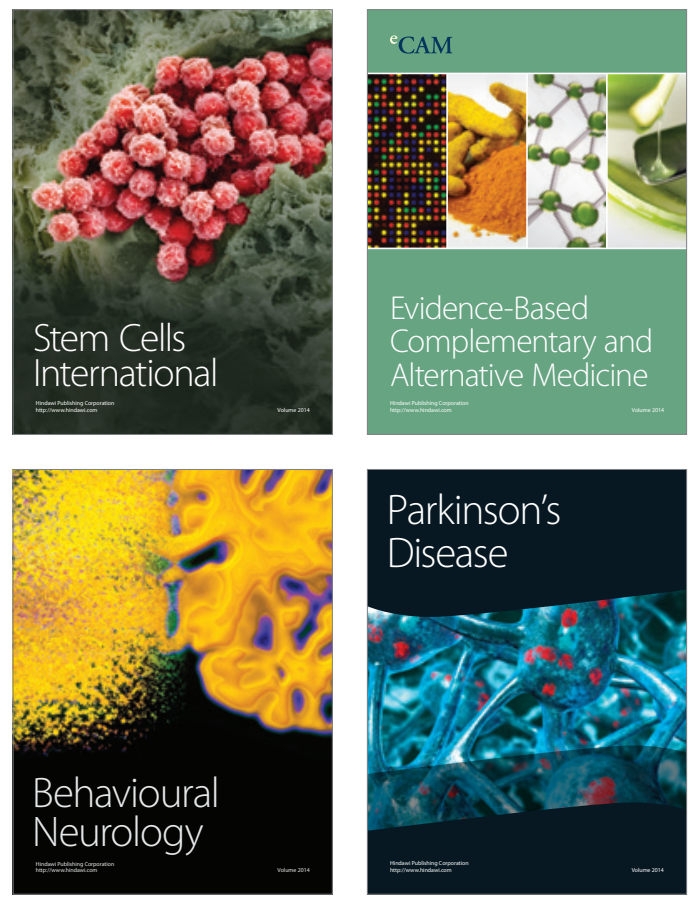
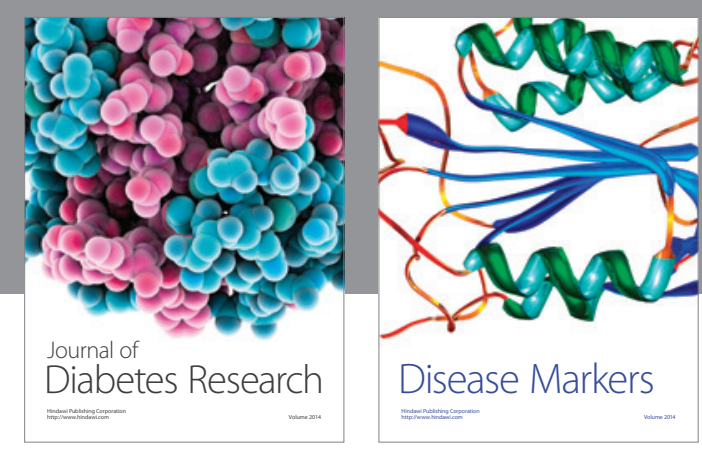

Disease Markers
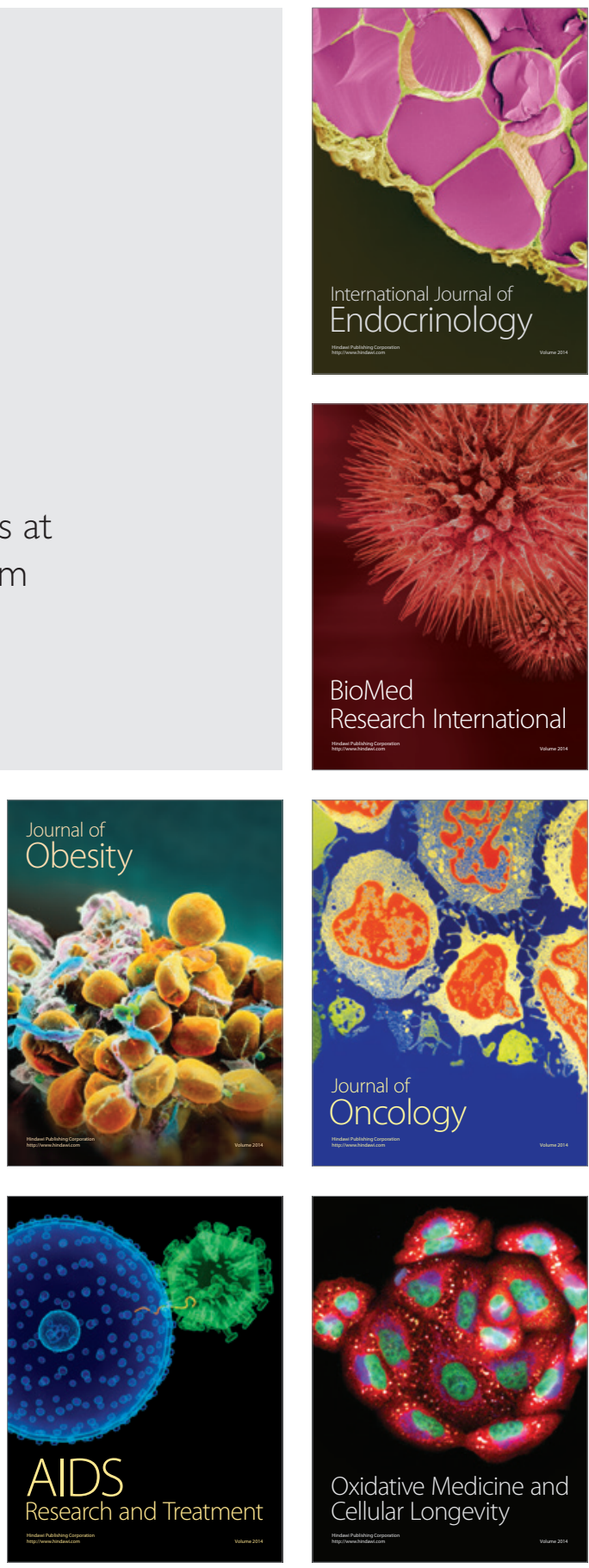